\title{
Clopidogrel discontinuation within the first year after coronary drug-eluting stent implantation: an observational study
}

\author{
Troels Thim', Martin Berg Johansen², Gro Egholm Chisholm², Morten Schmidt', Anne Kaltoft', \\ Henrik Toft Sørensen², Leif Thuesen', Steen Dalby Kristensen', Hans Erik Bøtker², Lars Romer Krusell', \\ Jens Flensted Lassen ${ }^{1}$, Per Thayssen ${ }^{3}$, Lisette Okkels Jensen ${ }^{3}$, Hans-Henrik Tilsted ${ }^{4}$ and Michael Maeng ${ }^{1 *}$
}

\begin{abstract}
Background: The impact of adherence to the recommended duration of dual antiplatelet therapy after first generation drug-eluting stent implantation is difficult to assess in real-world settings and limited data are available.

Methods: We followed 4,154 patients treated with coronary drug-eluting stents in Western Denmark for 1 year and obtained data on redeemed clopidogrel prescriptions and major adverse cardiovascular events (MACE, i.e., cardiac death, myocardial infarction, or stent thrombosis) from medical databases.

Results: Discontinuation of clopidogrel within the first 3 months after stent implantation was associated with a significantly increased rate of MACE at 1-year follow-up (hazard ratio (HR) 2.06; 95\% confidence interval (Cl): 1.08-3.93). Discontinuation 3-6 months (HR 1.29; 95\% Cl: 0.70-2.41) and 6-12 months (HR 1.29; 95\% Cl: 0.54-3.07) after stent implantation were associated with smaller, not statistically significant, increases in MACE rates. Among patients who discontinued clopidogrel, MACE rates were highest within the first 2 months after discontinuation.

Conclusions: Discontinuation of clopidogrel was associated with an increased rate of MACE among patients treated with drug-eluting stents. The increase was statistically significant within the first 3 months after drug-eluting stent implantation but not after 3 to 12 months.
\end{abstract}

Keywords: Percutaneous coronary intervention, Dual antiplatelet therapy, Drug-eluting stent, Clopidogrel

\section{Background}

Dual antiplatelet therapy (DAPT), i.e., aspirin in combination with a P2Y12 antagonist, has been shown to reduce occurrence of ischemic events after coronary stent implantation in randomized clinical trials [1,2]. In real-world settings, however, the level of adherence to recommended DAPT is difficult to assess and its influence on outcomes is less well known. Moreover, the optimal duration of DAPT after coronary stent implantation is disputed [3].

Twelve months of DAPT after percutaneous coronary intervention (PCI) with coronary stent implantation has been recommended in Denmark since November 2002. This recommendation is based on interpretation

\footnotetext{
* Correspondence: michael.maeng@ki.au.dk

'Department of Cardiology, Aarhus University Hospital, Aarhus, Denmark

Full list of author information is available at the end of the article
}

of results of existing randomized clinical trials [1,2]. In such trials, we expect adherence to treatment to be high owing to patient selection, trial-related follow-up, and cost-free provision of the platelet inhibitor. Adherence to DAPT in real-world settings is most likely lower than in these randomized trials. Assessment of adherence levels and risks associated with discontinuation of DAPT within the first year after coronary stent implantation is needed in real-world settings.

Danish medical registries allow validated monitoring of coronary interventions, prescription redemption, and clinical outcomes [4-9]. Based on data from these registries, we report rates of discontinuation of clopidogrel treatment after coronary drug-eluting stent (DES) implantation and assess the risk of associated adverse events.

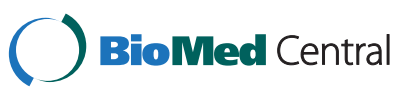

(c) 2014 Thim et al.; licensee BioMed Central Ltd. This is an Open Access article distributed under the terms of the Creative Commons Attribution License (http://creativecommons.org/licenses/by/4.0), which permits unrestricted use, distribution, and reproduction in any medium, provided the original work is properly credited. The Creative Commons Public Domain Dedication waiver (http://creativecommons.org/publicdomain/zero/1.0/) applies to the data made available in this article, unless otherwise stated 


\section{Methods}

According to the Central Denmark Region Committees on Health Research Ethics, this study could be conducted without an approval from the Committees.

\section{Setting}

We conducted this population-based cohort study, retrospectively, using medical registries in Western Denmark, which has approximately three million inhabitants (55\% of the Danish population). The Danish National Health Service provides universal tax-supported health care, guaranteeing unfettered access to general practitioners and hospitals. Costs of prescription medications, including clopidogrel, are partially reimbursed. Accurate and unambiguous linkage of data from all registries at the individual level is possible in Denmark using the unique central personal registry number assigned to every Danish citizen at birth or upon immigration [9].

\section{Patients and procedures}

We used the Western Denmark Heart Registry (WDHR) [10] to identify all PCI procedures performed between 1 January 2003 and 30 June 2005 [11-13]. For each patient, the first PCI procedure with implantation of one or more coronary DES during the inclusion period was defined as the "index PCI procedure" and the date of that procedure as the "index date". Patients treated with balloon angioplasty without stenting or with bare metal stents alone were excluded. Only first-generation DES, i.e., sirolimus-eluting (SES) (Cypher, Cordis Corp., Johnson \& Johnson, Warren, New Jersey) and paclitaxel-eluting stents (PES) (Taxus, Boston Scientific, Nattick, Massachusetts) were in use during the inclusion period.

The cardiac intervention centers in Western Denmark each perform more than 1,200 PCI procedures per year. The interventions were performed according to current standards including selection of interventional strategy (e.g., pre- or post-dilatation, choice of stent, direct stenting, and administration of periprocedural glycoprotein IIb/IIIa inhibitors).

\section{Patient characteristics}

We obtained information from Danish National Registry of Patients on potential confounders (diabetes and hypertension) between 1977 and the index date [5]. To ensure complete identification of patients with diabetes, we also searched the Danish National Prescription Database for any use of antidiabetic drugs among study participants since 1994 [14]. From the WDHR, we retrieved procedure data, including date of index $\mathrm{PCI}$, indication for PCI (ST-segment elevation myocardial infarction (MI), non-ST-segment elevation myocardial infarction MI or unstable angina pectoris, or stable angina pectoris), number of treated arteries (1, 2, or 3 or more), number of implanted stents (1, 2, or 3 or more), lesion type (A, B1, B2, or C), and stent type.

\section{Medication use}

We used the Danish National Prescription Database to identify all redeemed prescriptions for clopidogrel [14]. Clopidogrel is available only by prescription in Denmark.

The recommended daily maintenance dose of clopidogrel for secondary prevention of ischemic vascular events is $75 \mathrm{mg}$ (one tablet) daily for 12 months following PCI. Thus, for study purposes, the number of days supplied from a redeemed clopidogrel prescription corresponded to the number of tablets in the package. We computed the number of days exposed by adding 14 days to the number of days supplied. This buffer allowed for a 14-day gap to occur between redeemed prescriptions before a patient was considered to have discontinued clopidogrel. This method is well-established [15-17] and a 14-day gap has been used in previous studies [18].

We also identified redeemed prescriptions for aspirin, other nonselective non-steroidal anti-inflammatory drugs, selective cyclooxygenase- 2 inhibitors, proton pump inhibitors, calcium channel blockers, statins, vitamin $\mathrm{K}$ antagonists, and systemic glucocorticoids.

\section{Major adverse events}

In line with the recommended duration of clopidogrel treatment, we recorded occurrence of major adverse cardiovascular events (MACE) during 12 months after the index date. We defined MACE as the first occurrence of cardiac death, myocardial infarction MI, or definite stent thrombosis (ST). A committee of cardiac specialists, blinded to the history of medication use, reviewed relevant medical records to determine occurrence of definite stent thrombosis ST and cardiac death.

\section{Cardiac death}

We obtained data on all-cause mortality from the Danish Civil Registration System [9]. The committee of cardiac specialists reviewed original death certificates obtained from the National Registry of Causes of Deaths [6]. Deaths were classified as either cardiac or non-cardiac based on the underlying cause recorded on the death certificates. We defined cardiac death as known cardiac death, unwitnessed death, or death from unknown causes.

\section{Myocardial infarction (MI)}

We used the Danish National Registry of Patients to identify hospital admissions with MI as discharge diagnosis [5]. 


\section{Stent thrombosis (ST)}

Based on review of medical records and angiograms, the committee of cardiac specialists adjudicated the occurrence of definite ST according to Academic Research Consortium definitions [19].

\section{Statistical analysis}

We characterized the patients using medical, procedural, and demographic variables and followed all patients from their index date until date of death or completion of 12 months of follow up.

To describe the pattern of clopidogrel compliance, we first calculated the proportion of patients still alive who had prescription coverage for clopidogrel on each day of follow up. We also calculated the mean and median proportion of days within the first year after stent implantation with prescription coverage for clopidogrel among patients not experiencing MACE.

We then estimated the effect of discontinuing clopidogrel treatment. We defined discontinuation as a gap between prescription redemptions of more than 14 days. We estimated the effect separately according to the time of discontinuation, i.e., within the first 3 months (day 1 through 91), 3 to 6 months (day 92 through 182), or 6 to 12 months (day 183 through 365) after the index PCI procedure. We estimated hazard ratios using a Cox proportional hazards regression model. Hazard ratios were adjusted for potential confounders (age, gender, year of index PCI, indication for PCI, comorbidity level (using Charlson Comorbidity Index scores)) and time-varying use (calculated from the number of days exposed) of aspirin, other nonselective non-steroidal anti-inflammatory drugs, and proton pump inhibitors. Patients entered the study at the time of their first clopidogrel prescription redemption after the index date (delayed entry). Patients contributed to time at risk as current users of clopidogrel as long as they had prescription coverage for clopidogrel. From the time point of discontinuation, patients contributed time at risk according to their time window of discontinuation [15-17].

\section{Results}

The study included 4,154 patients treated with DES. Of these, 2,570 patients were treated with implantation of SES, 1,525 patients with PES, and 59 patients with SES and PES. Patient and procedure characteristics are shown in Table 1.

\section{Rates of clopidogrel treatment discontinuation}

In Figure 1, the proportion of patients with prescription coverage for clopidogrel on each day of follow up is plotted against time since the index PCI procedure date. There was a drop in prescription coverage between 3 and 4 months after the index PCI procedure, and again
Table 1 Patient and procedure characteristics

\begin{tabular}{|c|c|c|}
\hline & $\mathrm{N}=4,154^{*}$ & $\%$ \\
\hline Female & 1,127 & 27.1 \\
\hline \multicolumn{3}{|l|}{ Age group (years) } \\
\hline$<60$ & 1,659 & 39.9 \\
\hline $60-70$ & 1,316 & 31.7 \\
\hline $70+$ & 1,179 & 28.4 \\
\hline \multicolumn{3}{|l|}{ Medication uset } \\
\hline Clopidogrel & 3,931 & 94.6 \\
\hline Proton pump inhibitors & 955 & 23.0 \\
\hline Aspirin & 3,718 & 89.5 \\
\hline Vitamin $\mathrm{K}$ antagonists & 301 & 7.2 \\
\hline Nonselective NSAIDs & 509 & 12.3 \\
\hline COX-2 inhibitors & 388 & 9.3 \\
\hline Oral glucocorticoids & 309 & 7.4 \\
\hline Calcium channel blockers & 1,153 & 27.8 \\
\hline Statins & 3,606 & 86.8 \\
\hline \multicolumn{3}{|l|}{ Comorbidities $\neq$} \\
\hline Diabetes & 586 & 14.1 \\
\hline Hypertension & 178 & 4.3 \\
\hline \multicolumn{3}{|l|}{ Year of study entry } \\
\hline 2003 & 847 & 20.4 \\
\hline 2004 & 1,836 & 44.2 \\
\hline 2005 & 1,471 & 35.4 \\
\hline \multicolumn{3}{|l|}{ PCI Indication } \\
\hline STEMI & 844 & 20.3 \\
\hline UAP/NSTEMI & 1,277 & 30.7 \\
\hline SAP & 1,902 & 45.8 \\
\hline Other & 131 & 3.2 \\
\hline \multicolumn{3}{|l|}{ Number of treated arteries§ } \\
\hline 1 & 2,877 & 69.3 \\
\hline 2 & 1,057 & 25.4 \\
\hline 3 & 212 & 5.1 \\
\hline \multicolumn{3}{|l|}{ Number of Stents§ } \\
\hline 1 & 3,301 & 79.5 \\
\hline 2 & 631 & 15.2 \\
\hline $3+$ & 208 & 5.0 \\
\hline \multicolumn{3}{|l|}{ Lesion Type§ $\|$} \\
\hline A & 898 & 21.6 \\
\hline B & 2,165 & 52.1 \\
\hline C & 1,091 & 26.3 \\
\hline
\end{tabular}

*Drug-eluting stents only $(n=3,548)$ and combination of drug-eluting stents and bare metal stents $(\mathrm{n}=606)$

tAny prescription redemption during follow up. \#Registered between 1977 and the index PCI date

§Data were not available on number of treated arteries for 112 patients, on the number of stents for 62 patients, and on lesion type for 6 patients.

|Lesion classification: $A=$ non-complicated, length $<10 \mathrm{~mm} ; \mathrm{B}=$ irregular, length $10-20 \mathrm{~mm}$; $\mathrm{C}=$ irregular, side branch, 90 degrees, chronic occlusion, length $20 \mathrm{~mm}$ Abbreviations: COX cyclooxygenase, NSAIDs nonsteroidal anti-inflammatory drugs, $P C l$ percutaneous coronary intervention, STEMI ST-segment elevation myocardial infarction, SAP stable angina pectoris, UAP unstable angina pectoris, NSTEMI non-ST-segment elevation myocardial infarction. 


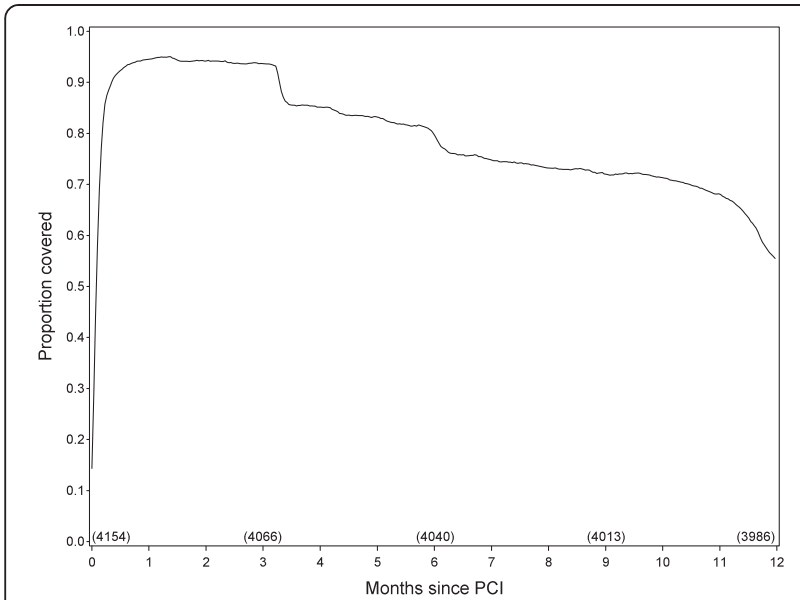

Figure 1 Proportion of patients covered by a prescription for clopidogrel on each day during follow up.

a smaller drop after about 6 months. The percentage of patients who never redeemed a prescription for clopidogrel during follow up was 5.4\%. Among the 3,815 eventfree survivors, the mean percentage of days covered by a clopidogrel prescription was 81\% (median: 96\%).

\section{Risk associated with clopidogrel treatment discontinuation}

Figure 2 shows the cumulative incidence of MACE during the first year after the index PCI procedure. The risk of MACE increased most within the first 2 weeks following the procedure (approximately $3 \%$ ) and then increased more gradually during the remainder of the one-year study period (overall 1 -year risk was approximately $6 \%$ ). Figure 3 shows the cumulative incidence of MACE over time starting from the time-point of discontinuation. The increase in cumulative risk of MACE was highest within the first 2 months following discontinuation.

Table 2 shows crude and adjusted hazard ratios for discontinuation of clopidogrel treatment. The 1-year cumulative MACE rate among patients covered by clopidogrel prescriptions for the full year was 3.9\%. Discontinuation of clopidogrel within the first 3 months after PCI was associated with an increased rate of MACE (approximately 2fold) and cardiac death (almost 5-fold). The risk estimates for the individual components of the combined outcome were also increased, with wider confidence intervals due to fewer events. Definite ST as an individual outcome was too rare within the first 3 months to allow for statistical inference. When discontinuation of clopidogrel occurred later than 3 months following PCI, differences in rates were not statistically significant, however, the hazard ratios suggested that risk of MACE was increased by approximately $30 \%$, cardiac death by $80 \%$, and MI by $10 \%$ when clopidogrel was discontinued later than 3 months following PCI. ST was rare and clopidogrel discontinuation between 3-6 months was associated with a nonsignificant 7 -fold higher risk of ST, corresponding to an almost 3\% risk of ST in this subgroup.

Patients who never redeemed a single clopidogrel prescription were not included in the analyses described above. Among these patients, the cumulative incidence of MACE was $48 \%$ within one week, $59 \%$ within one month, $61 \%$ within 3 months, and $63 \%$ within one year following PCI. Thus, these patients experienced very high early MACE rates, but rates after 3 months were

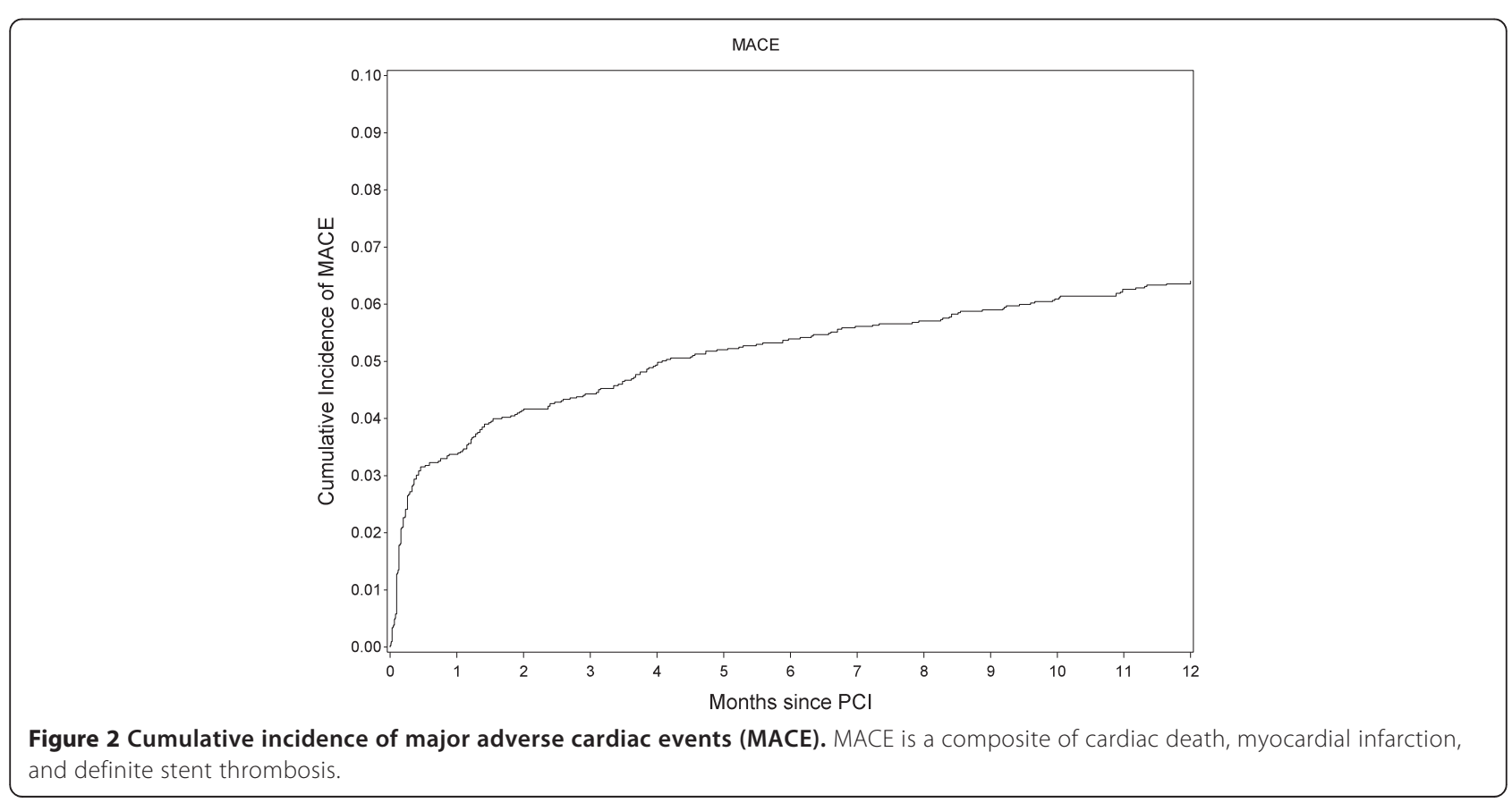




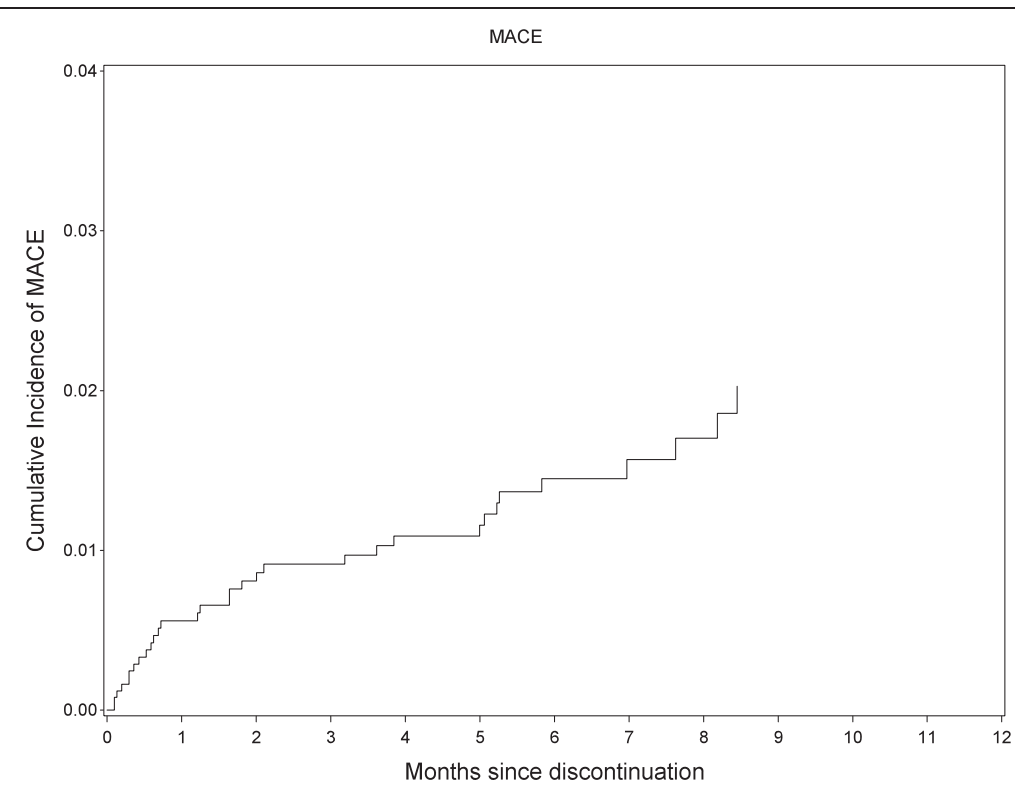

Figure 3 Cumulative incidence of major adverse cardiac events (MACE) following discontinuation of clopidogrel. MACE is a composite of cardiac death, myocardial infarction, and definite stent thrombosis.

comparable to that of the overall patient population, as shown in Figure 2. Early events, such as in-hospital death, may have prevented some of these patients from ever redeeming a clopidogrel prescription.

\section{Discussion}

Our main findings from this study of 4,154 consecutive real-world patients treated with first-generation DES are that discontinuation of clopidogrel was common and that discontinuation within the first 3 months after stent implantation was associated with an approximately twofold increase in risk of MACE and an almost 5-fold increase in risk of cardiac death.

\section{Registry data}

In cohort studies, premature clopidogrel discontinuation after DES implantation is fairly common. Data are conflicting on whether discontinuation, at least beyond the first 4-6 months, is associated with adverse events. These conflicting results may reflect major differences among these studies, including data acquisition, study design, and statistical approach.

Clopidogrel treatment is generally recommended for 12 months after DES implantation. Rates of clopidogrel discontinuation within these 12 months have been reported to be $14 \%$ within the first month [20], $28 \%$ by 6 months [18], and $4 \%-38 \%$ by 12 months [21-26]. The discontinuation rate reported in our study is similar in magnitude to that of most other reports [18,20-22,25,26].

The timing of clopidogrel discontinuation within the first year appears to be of major importance. Patients discontinuing DAPT within 7, 8-30, or $>30$ days after
PCI due to non-compliance or bleeding had a 7-fold, 2fold, and 1.3-fold higher risk of MACE, respectively [26]. Among patients with MI, clopidogrel discontinuation within the first month after coronary stent implantation has been associated with a 9-fold increased risk of death by 12 months [20]. Discontinuation within the first year,

Table 2 Hazard ratios (HRs) for discontinuation of clopidogrel treatment

\begin{tabular}{llll}
\hline $\begin{array}{l}\text { Time following } \\
\text { DES implantation }\end{array}$ & HR (95\% Cl) & $\begin{array}{l}\text { Adjusted HR } \\
(\mathbf{9 5 \%} \mathbf{C l})\end{array}$ \\
\hline MACE & 0-3 months & $2.48(1.30-4.71)$ & $2.06(1.08-3.93)$ \\
& 3-6 months & $1.26(0.68-2.33)$ & $1.29(0.70-2.41)$ \\
& 6-12 months & $1.26(0.53-2.99)$ & $1.29(0.54-3.07)$ \\
Cardiac death & 0-3 months & $6.84(3.06-15.3)$ & $4.80(2.13-10.8)$ \\
& 3-6 months & $1.95(0.72-5.30)$ & $1.85(0.68-5.04)$ \\
& 6-12 months & $1.65(0.42-6.46)$ & $1.74(0.45-6.78)$ \\
Myocardial infarction & 0-3 months & $2.05(0.93-4.53)$ & $1.84(0.83-4.09)$ \\
& 3-6 months & $1.08(0.51-2.28)$ & $1.14(0.54-2.43)$ \\
& 6-12 months & $1.09(0.36-3.35)$ & $1.09(0.35-3.34)$ \\
Definite stent & 0-3 months & - & - \\
thrombosis & 3-6 months & $6.04(0.52-70.2)$ & $7.14(0.61-83.7)$ \\
\hline & $6-12$ months & - & - \\
\hline
\end{tabular}

MACE is a composite of cardiac death, myocardial infarction, and definite stent thrombosis.

Abbreviations: $\mathrm{HR}$ hazard ratio, $\mathrm{Cl}$ confidence interval.

Hazard ratios were adjusted for age, gender, year of index $\mathrm{PCl}, \mathrm{PCl}$ indication, comorbidity level (using Charlson Comorbidity Index scores), and time-varying use (calculated from the number of days exposed) of aspirin, other NSAIDs, and proton pump inhibitors.

0-3 months = day 1 through $91 ; 3$ to 6 months = day 92 through $182 ; 6$ to 12 months = day 183 through 365 . 
particularly within the first month, has been associated with adverse events [21]. Based on a landmark approach, 3 studies evaluating event-free patients after 4-6-months of follow-up found that continued use of P2Y12 antagonists did not reduce the risk of adverse events $[22,27,28]$, while 2 other studies showed that it reduced the risk $[21,29]$. Regional differences, particularly socio-economic factors affecting compliance, may explain this discrepancy in part. In addition, the landmark approach is limited by the healthy survivor effect. Further, in all the studies described above, information about clopidogrel adherence relied on self-reports by patients or their relatives during visits or telephone interviews. Such contacts likely influenced clopidogrel compliance positively, making the data subject to non-differential misclassification bias.

A unique feature of the current study is the linkage of Danish national registries, thereby avoiding the misclassification bias associated with self-reporting. Only a single study previously linked data from a national prescription registry with clinical outcomes to assess the impact of premature clopidogrel discontinuation after DES implantation [18]. Similar to our findings, $28 \%$ of study patients discontinued clopidogrel within 6 months after their PCI procedure, and patients who discontinued clopidogrel within the first 6 months had a 2-fold higher risk of death at 12 months. In contrast to this earlier study, the current study included patients younger than 65 years, examined occurrence of MI and ST, and assessed the risk of discontinuing clopidogrel for 3 time intervals.

Individual variation in platelet response to clopidogrel is a subject of debate, providing some of the rationale behind development of newer and currently more expensive platelet inhibitors, such as ticagrelor and prasugrel $[30,31]$. While the clinical benefits of the newer platelet inhibitors are small compared to clopidogrel, they become significant in large populations of patients with acute coronary syndromes. At the same time, the impact of compliance to DAPT, at least within the first 3 months after $\mathrm{PCI}$, is major. Therefore, approaches to decrease rates of early DAPT discontinuation should be a major focus of future research and daily clinical practice.

\section{Randomized trial data}

Results from 2 on-going clinical trials are awaited $[32,33]$. Recently, it was reported that 3 months was non-inferior to 12 months of of DAPT after stent implantation [34]. The balance between reduction of ischemic events and the risk of bleeding may favor DAPT for 3 to 6 months after DES implantation and extending DAPT further might be associated with a risk of bleeding outweighing the benefit $[35,36]$. However, it has been found that DAPT for 1 year was superior to a 1-month regimen [2]. Recently, 4 randomized studies have been conducted, in which event-free patients were randomized to 3 [37], 6 [38,39] or 12 [40] months versus prolonged DAPT following PCI. All 4 trials reported no benefit of prolonged clopidogrel treatment [35,37-40]. Importantly, these randomized data, agree with our registry data based on consecutive real-world patients.

\section{Limitations}

The strength of this study lies in its use of populationbased registries with complete follow-up. However, a number of limitations should be acknowledged. First, some patients may have redeemed their prescriptions without taking all or any of the tablets. Moreover, temporary discontinuations $<14$ days were not detected. However, others have shown that such short discontinuations do not affect outcomes [24]. Second, aspirin use could not be completely assessed in this study, as aspirin is available without a prescription. This limitation may be relevant at least for ST [22]. However, low-dose aspirin used for secondary prevention of cardiovascular disease generally is prescribed by physicians because prescription costs are partly reimbursed through the national health insurance program. Third, despite adjustment for comorbidities, we cannot exclude residual confounding. Fourth, it has been reported that the positive effect of compliance with medication regimens is lower than estimated from observational studies [41]. The true protective effect of clopidogrel in routine clinical care patients thus may be lower than estimated here. Fifth, the decline in adherence to clopidogrel treatment after 3-4 months and 6 months after the index PCI procedure was likely caused by a combination of medical decisions for discontinuation and patients' lack of compliance $[20,23,26]$. Sixth, the results obtained are limited to the 2 first-generation DES. As newer DES are considered safer than the first generation DES [42], the impact of discontinuation of prolonged DAPT is likely to be lower with newer stents.

\section{Conclusion}

Discontinuation of clopidogrel was associated with an increased rate of MACE among patients treated with DES. The increase was statistically significant within the first 3 months after DES implantation but not after 3 to 12 months.

\footnotetext{
Abbreviations

Cl: Confidence interval; HR: Hazard ratio; MACE: Major adverse cardiovascular events; PCI: Percutaneous coronary intervention; WDHR: Western Denmark
} Heart Registry.

\section{Competing interests}

TT: Teaching honorarium from AstraZeneca. Travel grants from St. Jude Medical and The Medicines Company. MBJ, GEC, MS, HTS, LT, HEB, LRK, JFL, PT: None. SDK: Lecture fees from AstraZeneca, BMS, Eli Lilly, and The 
Medicines Company. AKK: Speakers fee from Cordis and St Jude Medical. Travel grants from Abbott, Biotronik, Cordis, Medtronic, Terumo, The Medicines Company, and St. Jude Medical. LOJ: Unrestricted grant from Terumo and honoraria from AstraZeneca. HHT: None. MM: Travel grants from Abbott, St. Jude Medical, Medtronic, Biotronik, and Terumo.

\section{Authors' contributions}

TT conception and design, data quisition, analysis and interpretation of data, and drafting of manuscript. MBJ: analysis and interpretation of data, and drafting of manuscript. GEC, MS, LT, HEB, SDK, LRK, AKK, JFL, PT, LOJ, HHT data quisition and review of manuscript. HTS conception and design and review of manuscript. MM conception and design, data quisition, analysis and interpretation of data, drafting and review of manuscript. All authors read and approved the final manuscript.

\section{Acknowledgements}

This is an academic study financed by the Departments of Cardiology and Clinical Epidemiology, Aarhus University Hospital, Denmark.

\section{Author details}

'Department of Cardiology, Aarhus University Hospital, Aarhus, Denmark. 2Department of Clinical Epidemiology, Aarhus University Hospital, Brendstrupgaardsvej 100, Aarhus, N 8200, Denmark. ${ }^{3}$ Department of Cardiology, Odense University Hospital, Odense, Denmark. ${ }^{4}$ Department of Cardiology, Aalborg University Hospital, Aalborg, Denmark.

Received: 4 May 2014 Accepted: 1 August 2014

Published: 13 August 2014

\section{References}

1. Mehta SR, Yusuf S, Peters RJ, Bertrand ME, Lewis BS, Natarajan MK, Malmberg K, Rupprecht H, Zhao F, Chrolavicius S, Copland I, Fox KA, Clopidogrel in Unstable angina to prevent Recurrent Events trial (CURE) Investigators: Effects of pretreatment with clopidogrel and aspirin followed by long-term therapy in patients undergoing percutaneous coronary intervention: the PCI-CURE study. Lancet 2001, 358:527-533.

2. Steinhubl SR, Berger PB, Mann JT III, Fry ET, DeLago A, Wilmer C, Topol EJ: Early and sustained dual oral antiplatelet therapy following percutaneous coronary intervention: a randomized controlled trial. JAMA 2002, 288:2411-2420.

3. Kleiman NS: Grabbing the horns of a dilemma: the duration of dual antiplatelet therapy after stent implantation. Circulation 2012, 125:1967-1970.

4. Sørensen HT: Regional administrative health registries as a resource in clinical epidemiology. Int J Risk Saf Med 1997, 10:1-22

5. Andersen TF, Madsen M, Jorgensen J, Mellemkjoer L, Olsen JH: The Danish National Hospital Register. A valuable source of data for modern health sciences. Dan Med Bull 1999, 46:263-268.

6. Juel K, Helweg-Larsen K: The Danish registers of causes of death. Dan Med Bull 1999, 46:354-357.

7. Frank L: Epidemiology. When an entire country is a cohort. Science 2000, 287:2398-2399.

8. Madsen M, Davidsen M, Rasmussen S, Abildstrom SZ, Osler M: The validity of the diagnosis of acute myocardial infarction in routine statistics: a comparison of mortality and hospital discharge data with the Danish MONICA registry. J Clin Epidemiol 2003, 56:124-130.

9. Pedersen CB, Gotzsche H, Moller JO, Mortensen PB: The Danish Civil Registration System. A cohort of eight million persons. Dan Med Bull 2006, 53:441-449.

10. Schmidt M, Maeng M, Jakobsen CJ, Madsen M, Thuesen L, Nielsen PH, Botker HE, Sorensen HT: Existing data sources for clinical epidemiology: the Western Denmark Heart Registry. Clin Epidemiol 2010, 2:137-144.

11. Jensen LO, Tilsted HH, Thayssen P, Kaltoft A, Maeng M, Lassen JF, Hansen KN, Madsen M, Ravkilde J, Johnsen SP, Sørensen HT, Thuesen L: Paclitaxel and sirolimus eluting stents versus bare metal stents: long-term risk of stent thrombosis and other outcomes. From the Western Denmark Heart Registry. Eurolntervention 2010, 5:898-905

12. Kaltoft A, Jensen LO, Maeng M, Tilsted HH, Thayssen P, Bottcher M, Lassen JF, Krusell LR, Rasmussen K, Hansen KN, Pedersen L, Johnsen SP, Sørensen HT, Thuesen L: 2-year clinical outcomes after implantation of sirolimus-eluting, paclitaxel-eluting, and bare-metal coronary stents: results from the WDHR (Western Denmark Heart Registry). J Am Coll Cardiol 2009, 53:658-664.

13. Jensen LO, Maeng M, Kaltoft A, Thayssen P, Hansen HH, Bottcher M, Lassen JF, Krussel LR, Rasmussen K, Hansen KN, Pedersen L, Johnsen SP, Soerensen $H T$, Thuesen L: Stent thrombosis, myocardial infarction, and death after drug-eluting and bare-metal stent coronary interventions. J Am Coll Cardiol 2007, 50:463-470.

14. Wallach Kildemoes H, Toft Sørensen H, Hallas J: The Danish National Prescription Registry. Scand J Public Health 2011, 39:38-41.

15. Schmidt M, Johansen MB, Robertson DJ, Maeng M, Kaltoft A, Jensen LO, Tilsted HH, Botker HE, Sorensen HT, Baron JA: Use of clopidogrel and calcium channel blockers and risk of major adverse cardiovascular events. Eur J Clin Invest 2012, 42:266-274.

16. Schmidt M, Johansen MB, Robertson DJ, Maeng M, Kaltoft A, Jensen LO, Tilsted HH, Botker HE, Sorensen HT, Baron JA: Concomitant use of clopidogrel and proton pump inhibitors is not associated with major adverse cardiovascular events following coronary stent implantation. Aliment Pharmacol Ther 2012, 35:165-174.

17. Schmidt M, Johansen MB, Maeng M, Kaltoft A, Jensen LO, Tilsted HH, Botker HE, Baron JA, Sorensen HT: Concomitant use of clopidogrel and statins and risk of major adverse cardiovascular events following coronary stent implantation. Br J Clin Pharmacol 2012, 74:161-170.

18. Ko DT, Chiu M, Guo H, Austin PC, Marquis JF, Tu JV: Patterns of use of thienopyridine therapy after percutaneous coronary interventions with drug-eluting stents and bare-metal stents. Am Heart J 2009, 158:592-598.

19. Cutlip DE, Windecker S, Mehran R, Boam A, Cohen DJ, van Es GA, Steg PG, Morel MA, Mauri L, Vranckx P, McFadden E, Lansky A, Hamon M, Krucoff MW, Serruys PW, Academic Research Consortium: Clinical end points in coronary stent trials: a case for standardized definitions. Circulation 2007, 115:2344-2351.

20. Spertus JA, Kettelkamp R, Vance C, Decker C, Jones PG, Rumsfeld JS, Messenger JC, Khanal S, Peterson ED, Bach RG, Krumholz HM, Cohen DJ: Prevalence, predictors, and outcomes of premature discontinuation of thienopyridine therapy after drug-eluting stent placement: results from the PREMIER registry. Circulation 2006, 113:2803-2809.

21. Rossini R, Capodanno D, Lettieri C, Musumeci G, Nijaradze T, Romano M Lortkipanidze N, Cicorella N, Biondi ZG, Sirbu V, Izzo A, Guagliumi G, Valsecchi O, Gavazzi A, Angiolillo DJ: Prevalence, predictors, and long-term prognosis of premature discontinuation of oral antiplatelet therapy after drug eluting stent implantation. Am J Cardiol 2011, 107:186-194.

22. Kimura T, Morimoto T, Nakagawa Y, Tamura T, Kadota K, Yasumoto H, Nishikawa H, Hiasa Y, Muramatsu T, Meguro T, Inoue N, Honda H, Hayashi Y, Miyazaki S, Oshima S, Honda T, Shiode N, Namura M, Sone T, Nobuyoshi M, Kita T, Mitsudo K, j-Cypher Registry Investigators: Antiplatelet therapy and stent thrombosis after sirolimus-eluting stent implantation. Circulation 2009, 119:987-995

23. Ferreira-Gonzalez I, Marsal JR, Ribera A, Permanyer-Miralda G, Garcia-Del BB, Marti G, Cascant P, Martin-Yuste V, Brugaletta S, Sabate M, Alfonso F, Capote ML, De La Torre JM, Ruíz-Lera M, Sanmiguel D, Cárdenas M, Pujol B, Baz JA Iñiguez A, Trillo R, González-Béjar O, Casanova J, Sánchez-Gila J, García-Dorado D: Background, incidence, and predictors of antiplatelet therapy discontinuation during the first year after drug-eluting stent implantation. Circulation 2010, 122:1017-1025

24. Ferreira-Gonzalez I, Marsal JR, Ribera A, Permanyer-Miralda G, Garcia-Del BB, Marti G, Cascant P, Masotti-Centol M, Carrillo X, Mauri J, Batalla N, Larrousse E, Martín E, Serra A, Rumoroso JR, Ruiz-Salmerón R, de la Torre JM, Cequier A, Gómez-Hospital JA, Alfonso F, Martín-Yuste V, Sabatè M, García-Dorado D: Double antiplatelet therapy after drug-eluting stent implantation: risk associated with discontinuation within the first year. J Am Coll Cardiol 2012, 60:1333-1339.

25. Roy P, Bonello L, Torguson R, Okabe T, Pinto Slottow TL, Steinberg DH, Kaneshige K, Xue Z, Satler LF, Kent KM, Suddath WO, Pichard AD, Lindsay J, Waksman R: Temporal relation between Clopidogrel cessation and stent thrombosis after drug-eluting stent implantation. Am J Cardiol 2009, 103:801-805.

26. Mehran R, Baber U, Steg PG, Ariti C, Weisz G, Witzenbichler B, Henry TD, Kini AS, Stuckey T, Cohen DJ, Berger PB, lakovou I, Dangas G, Waksman R, Antoniucci D, Sartori S, Krucoff MW, Hermiller JB, Shawl F, Gibson CM, Chieffo A, Alu M, Moliterno DJ, Colombo A, Pocock S: Cessation of dual antiplatelet treatment and cardiac events after percutaneous coronary intervention (PARIS): 2 year results from a prospective observational study. Lancet 2013, 382:1714-1722. 
27. Shin DH, Chae IH, Youn TJ, Cho SI, Kwon DA, Suh JW, Chang HJ, Cho YS, Chung WY, Choi YJ, Gwon HC, Han KR, Choi DJ: Reasonable duration of Clopidogrel use after drug-eluting stent implantation in Korean patients. Am J Cardiol 2009, 104:1668-1673.

28. Tada T, Natsuaki M, Morimoto T, Furukawa Y, Nakagawa Y, Byrne RA, Kastrati A, Kadota K, Iwabuchi M, Shizuta S, Tazaki J, Shiomi H, Abe M, Ehara N, Mizoguchi T, Mitsuoka H, Inada T, Araki M, Kaburagi S, Taniguchi R, Eizawa H, Nakano A, Suwa S, Takizawa A, Nohara R, Fujiwara H, Mitsudo K, Nobuyoshi M, Kita T, Kimura T, et al: Duration of dual antiplatelet therapy and long-term clinical outcome after coronary drug-eluting stent implantation: landmark analyses from the CREDO-Kyoto PCI/CABG Registry Cohort-2. Circ Cardiovasc Interv 2012, 5:381-391.

29. Eisenstein EL, Anstrom KJ, Kong DF, Shaw LK, Tuttle RH, Mark DB, Kramer JM, Harrington RA, Matchar DB, Kandzari DE, Peterson ED, Schulman KA, Califf RM: Clopidogrel use and long-term clinical outcomes after drug-eluting stent implantation. JAMA 2007, 297:159-168.

30. Wiviott SD, Braunwald E, McCabe CH, Montalescot G, Ruzyllo W, Gottlieb S, Neumann FJ, Ardissino D, De Servi S, Murphy SA, Riesmeyer J, Weerakkody G, Gibson CM, Antman EM, TRITON-TIMI 38 Investigators: Prasugrel versus clopidogrel in patients with acute coronary syndromes. N Engl J Med 2007, 357:2001-2015.

31. Wallentin L, Becker RC, Budaj A, Cannon CP, Emanuelsson H, Held C, Horrow J, Husted S, James S, Katus H, Mahaffey KW, Scirica BM, Skene A, Steg PG, Storey RF, Harrington RA, PLATO Investigators, Freij A, Thorsén M: Ticagrelor versus clopidogrel in patients with acute coronary syndromes. $N$ Engl J Med 2009, 361:1045-1057.

32. Mauri L, Kereiakes DJ, Normand SL, Wiviott SD, Cohen DJ, Holmes DR, Bangalore S, Cutlip DE, Pencina M, Massaro JM: Rationale and design of the dual antiplatelet therapy study, a prospective, multicenter, randomized, double-blind trial to assess the effectiveness and safety of 12 versus 30 months of dual antiplatelet therapy in subjects undergoing percutaneous coronary intervention with either drug-eluting stent or bare metal stent placement for the treatment of coronary artery lesions. Am Heart J 2010, 160:1035-1041.

33. Byrne RA, Schulz S, Mehilli J, lijima R, Massberg S, Neumann FJ, ten Berg JM, Schomig A, Kastrati A: Rationale and design of a randomized, doubleblind, placebo-controlled trial of 6 versus 12 months clopidogrel therapy after implantation of a drug-eluting stent: The Intracoronary Stenting and Antithrombotic Regimen: Safety And EFficacy of 6 Months Dual Antiplatelet Therapy After Drug-Eluting Stenting (ISAR-SAFE) study. Am Heart J 2009, 157:620-624.

34. Feres F, Costa RA, Abizaid A, Leon MB, Marin-Neto JA, Botelho RV, King SB III, Negoita M, Liu M, de Paula JE, Mangione JA, Meireles GX, Castello HJ Jr, Nicolela EL Jr, Perin MA, Devito FS, Labrunie A, Salvadori D Jr, Gusmão M, Staico R, Costa JR Jr, de Castro JP, Abizaid AS, Bhatt DL, OPTIMIZE Trial Investigators: Three vs twelve months of dual antiplatelet therapy after zotarolimus-eluting stents: the OPTIMIZE randomized trial. JAMA 2013, 310:2510-2522.

35. Cassese S, Byrne RA, Tada T, King LA, Kastrati A: Clinical impact of extended dual antiplatelet therapy after percutaneous coronary interventions in the drug-eluting stent era: a meta-analysis of randomized trials. Eur Heart J 2012, 33:3078-3087.

36. Pandit A, Giri S, Hakim FA, Fortuin FD: Shorter ( $</=6$ months) versus longer ( $>/=12$ months) duration dual antiplatelet therapy after drug eluting stents: A meta-analysis of randomized clinical trials. Catheter Cardiovasc Interv 2014, 10. doi:10.1002/ccd.25520.

37. Kim BK, Hong MK, Shin DH, Nam CM, Kim JS, Ko YG, Choi D, Kang TS, Park BE, Kang WC, Lee SH, Yoon JH, Hong BK, Kwon HM, Jang Y, RESET Investigators: A new strategy for discontinuation of dual antiplatelet therapy: the RESET Trial (REal Safety and Efficacy of 3-month dual antiplatelet Therapy following Endeavor zotarolimus-eluting stent implantation). J Am Coll Cardiol 2012, 60:1340-1348.

38. Valgimigli M, Campo G, Monti M, Vranckx P, Percoco G, Tumscitz C, Castriota F, Colombo F, Tebaldi M, Fuca G, Kubbajeh M, Cangiano E, Minarelli M, Scalone A, Cavazza C, Frangione A, Borghesi M, Marchesini J, Parrinello G, Ferrari R, Prolonging Dual Antiplatelet Treatment After Grading Stent-Induced Intimal Hyperplasia Study (PRODIGY) Investigators: Short- versus long-term duration of dual antiplatelet therapy after coronary stenting: a randomized multicentre trial. Circulation 2012, 125:2015-2026.

39. Gwon HC, Hahn JY, Park KW, Song YB, Chae IH, Lim DS, Han KR, Choi JH, Choi SH, Kang HJ, Koo BK, Ahn T, Yoon JH, Jeong MH, Hong TJ, Chung WY,
Choi YJ, Hur SH, Kwon HM, Jeon DW, Kim BO, Park SH, Lee NH, Jeon HK, Jang Y, Kim HS: Six-month versus 12-month dual antiplatelet therapy after implantation of drug-eluting stents: the Efficacy of Xience/Promus Versus Cypher to Reduce Late Loss After Stenting (EXCELLENT) randomized, multicenter study. Circulation 2012, 125:505-513.

40. Park SJ, Park DW, Kim YH, Kang SJ, Lee SW, Lee CW, Han KH, Park SW, Yun SC, Lee SG, Rha SW, Seong IW, Jeong MH, Hur SH, Lee NH, Yoon J, Yang JY, Lee BK, Choi YJ, Chung WS, Lim DS, Cheong SS, Kim KS, Chae JK, Nah DY, Jeon DS, Seung KB, Jang JS, Park HS, Lee K: Duration of dual antiplatelet therapy after implantation of drug-eluting stents. N Engl J Med 2010, 362:1374-1382.

41. LaFleur J, Nelson RE, Sauer BC, Nebeker JR: Overestimation of the effects of adherence on outcomes: a case study in healthy user bias and hypertension. Heart 2011, 97:1862-1869.

42. Bangalore S, Kumar S, Fusaro M, Amoroso N, Attubato MJ, Feit F, Bhatt DL Slater J: Short- and long-term outcomes with drug-eluting and bare-metal coronary stents: a mixed-treatment comparison analysis of 117762 patient-years of follow-up from randomized trials. Circulation 2012, 125:2873-2891.

doi:10.1186/1471-2261-14-100

Cite this article as: Thim et al.: Clopidogrel discontinuation within the first year after coronary drug-eluting stent implantation: an observational study. BMC Cardiovascular Disorders 2014 14:100.

\section{Submit your next manuscript to BioMed Central and take full advantage of:}

- Convenient online submission

- Thorough peer review

- No space constraints or color figure charges

- Immediate publication on acceptance

- Inclusion in PubMed, CAS, Scopus and Google Scholar

- Research which is freely available for redistribution

Submit your manuscript at www.biomedcentral.com/submit
C Biomed Central 